\title{
Phenotypic analysis of lymphocytes and monocytes/macrophages in peripheral blood and bronchoalveolar lavage fluid from patients with pulmonary sarcoidosis
}

\author{
J Wahlström, M Berlin, C M Sköld, H Wigzell, A Eklund, J Grunewald
}

\begin{abstract}
Background-The granulomatous inflammation in sarcoidosis is driven by the interplay between $T$ cells and macrophages. To gain a better understanding of this process the expression by these cells of cell surface activation markers, costimulatory molecules, and adhesion molecules was analysed.

Methods-CD4+ and CD8+ T lymphocytes from peripheral blood (PBL) or bronchoalveolar lavage (BAL) fluid, as well as paired peripheral blood monocytes and alveolar macrophages from 27 patients with sarcoidosis were analysed by flow cytometry.

Results-CD26, CD54, CD69, CD95, and gp240 were all overexpressed in $T$ cells from BAL fluid compared with those from PBL in both the CD4+ and CD8+ subsets, while CD57 was overexpressed only in BAL CD4+ cells. In contrast, CD28 tended to be underexpressed in the BAL $T$ cells. Monocyte/macrophage markers included CD11a, CD11b, CD11c, CD14, CD16, CD54, CD71, CD80 and CD86 and HLA class II. CD11a expression in alveolar macrophages (and peripheral blood monocytes) was increased in patients with active disease and correlated positively with the percentage of BAL lymphocytes. Expression of CD80 in macrophages correlated with the BAL CD4/CD8 ratio.

Conclusions-Our data indicate substantial activation of both CD4+ and CD8+ lung $T$ cells in sarcoidosis. There were also increased numbers of BAL lymphocytes whose phenotypic characteristics have earlier been associated with clonally expanded, replicatively senescent cells of the Th1 type.

(Thorax 1999;54:339-346)
\end{abstract}

Keywords: sarcoidosis; phenotype; T cells; macrophages

Sarcoidosis is a chronic granulomatous disease of unknown origin, primarily affecting the lungs. In early disease there is a mononuclear cell alveolitis dominated by activated CD4+ (helper/inducer) $\mathrm{T}$ cells and macrophages. The coordinated interplay between these cells leads to the characteristic formation of noncaseating granulomas and, in a subgroup of patients, to fibrosis and permanently impaired lung function. ${ }^{1}$
The antigen presenting capacity of lung cells has been the subject of several investigations. Dendritic cells are efficient with regard to antigen presenting capacity and are probably critical in primary immune responses, while alveolar macrophages have generally been considered to have poor antigen presenting capacity $^{2}$ and may even suppress $\mathrm{T}$ cell proliferation. ${ }^{3}$ They are, however, capable of processing and presenting intact antigens to specific $\mathrm{T}$ cell clones (J Grunewald et al, unpublished). Several studies have suggested an enhanced capacity of alveolar macrophages to function in sarcoidosis as efficient antigen presenters. ${ }^{45}$ Parameters affecting the ability of alveolar macrophages to present antigen to $\mathrm{T}$ cells include expression of co-stimulatory molecules such as CD80 and CD86 interacting with CD28 on $\mathrm{T}$ cells.

Besides cytokines, chemoattractants and co-stimulatory molecules, adhesion molecules play an important role in pulmonary inflammation. They mediate cell-cell and cell-matrix adhesion and can be grouped into distinct families based on their structures - for example, the integrins and members of the immunoglobulin superfamily.

The purpose of this study was to examine the phenotype of different cell populations in peripheral blood and bronchoalveolar lavage (BAL) fluid of patients with sarcoidosis, with the focus on activation markers, adhesion molecules, and co-stimulatory molecules. The cell subsets studied were CD4+ and CD8+ T cells in peripheral blood and BAL fluid, as well as peripheral blood monocytes and macrophages. We have evaluated differences in $\mathrm{T}$ cell and monocyte/macrophage phenotypic characteristics between peripheral blood and BAL fluid and, more specifically, have compared patients with active and inactive disease. We also attempted to correlate $\mathrm{T}$ cell phenotype with monocyte/macrophage phenotypes. The results obtained may aid the identification of critical cell surface molecules involved in the pathogenesis of sarcoidosis.

\section{Methods}

SUBJECTS

Twenty seven patients of mean age 42 years (range 24-61) with untreated sarcoidosis participated in the study. Thirteen had histologically proven disease, the remaining 14 had typical clinical and chest radiographic features. Nine of these 14 patients had a BAL $\mathrm{CD} 4 / \mathrm{CD} 8$ ratio greater than 4.0 , further 
Table 1 Characterisation of monoclonal antibodies used for staining of lymphocytes $(L)$ and monocytes/macrophages (M). FITC conjugated monoclonal antibodies unless otherwise stated

\begin{tabular}{|c|c|c|c|c|}
\hline $\begin{array}{l}\text { Monoclonal antibody } \\
\text { specificity }\end{array}$ & Alternative nomenclature & $\begin{array}{l}\text { Major function/ } \\
\text { marker of }\end{array}$ & Clone & $\begin{array}{l}\text { Used for } \\
\text { staining of }\end{array}$ \\
\hline CD11a & LFA-1 & Adhesion & MHM24 1 & $\mathrm{~L}+\mathrm{M}$ \\
\hline $\mathrm{CD} 11 \mathrm{~b}^{\star}$ & Mac-1, CR3 & Adhesion & $2 \mathrm{LPM} 19 \mathrm{c}^{1}$ & $\mathrm{M}$ \\
\hline $\mathrm{CD} 11 \mathrm{c}$ & p150,95, CR4 & Adhesion & $\mathrm{KB} 90^{1}$ & $\mathrm{M}$ \\
\hline CD14 & LPS receptor & Monocyte marker & TÜK4 ${ }^{1}$ & $\mathrm{M}$ \\
\hline CD16 & Fc $\gamma$ RIII & Subset marker & $3 \mathrm{G} 8^{3}$ & $\mathrm{M}$ \\
\hline CD26 & Ta-1 & Activation & $4 \mathrm{EL}-1 \mathrm{C} 7^{3}$ & $\mathrm{~L}$ \\
\hline CD28 & & Co-stimulation & CD28. $2^{4}$ & $\mathrm{~L}$ \\
\hline CD50 & ICAM-3 & Adhesion & $101-1 \mathrm{D} 2^{2}$ & $\mathrm{~L}$ \\
\hline CD54 & ICAM-1 & Adhesion & B-C $14^{2}$ & $\mathrm{~L}+\mathrm{M}$ \\
\hline CD57 & & Subset marker & $\mathrm{HNK}-1^{6}$ & $\mathrm{~L}$ \\
\hline CD69 & & Activation & $\mathrm{L}_{7}{ }^{6}$ & $\mathrm{~L}$ \\
\hline CD71 & Transferrin receptor & Activation & Ber-T9 ${ }^{1}$ & $\mathrm{~L}+\mathrm{M}$ \\
\hline CD80 & B7-1 & Co-stimulation & $\mathrm{BB}-1^{2}$ & $\mathrm{~L}+\mathrm{M}$ \\
\hline CD86 & B7-2 & Co-stimulation & BU $63^{2}$ & $\mathrm{~L}+\mathrm{M}$ \\
\hline CD95 & Fas & Apoptosis & $\mathrm{DX} 2^{5}$ & $\mathrm{~L}$ \\
\hline CTLA-4 + & & Inhibition & BNA3. $1^{5}$ & $\mathrm{~L}$ \\
\hline gp240† & & Activation & $\mathrm{B} 1.19 .2^{4}$ & $\overline{\mathrm{L}}$ \\
\hline HLA class II & HLA-DP, -DQ, -DR & Activation & $\mathrm{CR} 3 / 43^{1}$ & M \\
\hline
\end{tabular}

${ }^{1}$ Dako AS, Glostrup, Denmark; ${ }^{2}$ Serotec, Oxford, UK; ${ }^{3}$ Coulter, Hialeah, Florida, USA; ${ }^{4}$ Immunotech, Luminy, France; ${ }^{5}$ Pharmingen, La Jolla, California, USA; ${ }^{6}$ Becton Dickinson, San Jose, California, USA.

^Phycoerythrin-conjugated antibody.

†Unconjugated antibody.

supporting the diagnosis. ${ }^{6}$ Of the other five patients, two presented with classical Löfgren's syndrome, one had a positive Kveim test, and one displayed a sarcoidosis-like picture on computer tomographic scanning. Three of the patients were smokers, eight were ex-smokers, and 16 had never smoked. Disease activity was judged from symptoms, chest radiography, and pulmonary function tests using the criteria established by the World Association of Sarcoidosis and other Granulomatous Disorders (WASOG). ${ }^{7}$ The mean age of patients with active and inactive disease was 38 and 52 years, respectively $(\mathrm{p}=0.005)$. Paired samples of peripheral blood lymphocytes (PBL) and lung $\mathrm{T}$ cells recruited by BAL were obtained from 23 patients (15 with active disease), peripheral blood monocytes and alveolar macrophages were analysed in 19 patients (14 with active disease), and paired samples of PBL/BAL T cells and monocytes/macrophages were obtained from 16 patients (11 with active disease).

\section{BRONCHOALVEOLAR LAVAGE}

Bronchoalveolar lavage was performed as described previously. ${ }^{8}$ In brief, under local anaesthesia the flexible fibreoptic bronchoscope (Olympus BF Type 1TR; Olympus Optical Co Ltd, Tokyo, Japan) was wedged in a middle lobe bronchus and sterile phosphate

Table 2 General characteristics of cells obtained by bronchoalveolar lavage (BAL) and of peripheral blood lymphocytes (PBL) in patient subgroups

\begin{tabular}{lcl}
\hline & All patients & Active/inactive disease \\
\hline Recovery (\%) & $68.0(7.3)$ & $68.7(7.8) / 66.3(5.8)$ \\
Viability (\%) & $94.7(3.6)$ & $94.9(3.5) / 94.0(4.1)$ \\
Total cells $\left(\times 10^{6}\right)$ & $36.5(24.0)$ & $40.8(26.5) / 26.3(12.8)$ \\
Percentage of total BAL cells & & \\
$\quad$ Alveolar macrophages & $73.8(14.0)$ & $70.4(14.4) / 81.8(9.4)(\mathrm{p}<0.05)$ \\
Lymphocytes & $23.7(14.2)$ & $27.4(14.7) / 14.8(7.9)(\mathrm{p}<0.05)$ \\
Neutrophils & $2.0(2.5)$ & $1.8(2.0) / 2.6(3.6)$ \\
Eosinophils & $0.5(0.6)$ & $0.4(0.7) / 0.6(0.5)$ \\
Basophils & $0.0(0.1)$ & $0.0(0.06) / 0.1(0.1)$ \\
BAL CD4/CD8 & $6.7(5.2)$ & $8.5(5.5) / 3.4(1.6)(\mathrm{p}<0.01)$ \\
PBL CD4/CD8 & $3.1(1.9)$ & $3.2(1.6) / 2.9(2.4)$ \\
\hline
\end{tabular}

Values depict mean (SD) for all patients and mean values for patient subgroups. $p$ values are indicated only when $\mathrm{p}<0.05$; in all other cases there was no significant difference. buffered saline (PBS) solution at $37^{\circ} \mathrm{C}$ was instilled in five aliquots of $50 \mathrm{ml}$. After each instillation the fluid was gently aspirated and collected in a siliconised plastic bottle kept on ice.

PREPARATION OF CELLS

The BAL fluid was strained through a Dacron net (Millipore, Cork, Ireland), centrifuged at $400 \mathrm{~g}$ for 10 minutes at $4^{\circ} \mathrm{C}$, and the pellet was resuspended in RPMI 1640 medium (SigmaAldrich, UK). Cells were counted in a Bürker chamber and total cell viability (mean $=95 \%$ ) was determined by trypan blue exclusion. Smears for differential counts were prepared by cytocentrifugation (Cytospin 2; Shandon, Runcorn, Cheshire, UK) at $22 g$ for three minutes, after which the cells were stained with May-Grünwald-Giemsa. Ficoll-Hypaque (Pharmacia, Uppsala, Sweden) gradient centrifugation was used to separate peripheral blood mononuclear cells which were washed twice and diluted in RPMI 1640.

IMMUNOSTAINING AND FLOW CYTOMETRY

Antibodies used for phenotypic characterisation of lymphocytes and monocytes/ macrophages are listed in table 1. RPE-Cy5 conjugated anti-CD4 monoclonal antibodies, RPE conjugated anti-CD8 monoclonal antibodies, and FITC conjugated $\mathrm{F}\left(\mathrm{ab}^{\prime}\right)_{2}$ fragments of rabbit anti-mouse immunoglobulin were obtained from Dako (Glostrup, Denmark). Normal mouse serum from BALB/c mice was used to block inappropriate binding of rabbit anti-mouse immunoglobulin. The OKT3 (CD3) hybridoma was acquired from the American Type Culture Collection (ATCC, Rockville, Maryland, USA).

For surface antigen for which no direct labelled antibody was available, lymphocytes were incubated with unlabelled monoclonal antibody and washed twice; FITC conjugated $\mathrm{F}\left(\mathrm{ab}^{\prime}\right)_{2}$ fragments of rabbit anti-mouse immunoglobulin were added for detection of bound antibodies. Normal mouse serum diluted 1:500 was used to block remaining rabbit antimouse immunoglobulin before adding the RPE-Cy5 conjugated anti-CD4 and RPE conjugated anti-CD 8 monoclonal antibodies. Alternatively, cells were incubated with direct labelled antibody, washed twice, and resuspended in RPMI 1640 before adding anti-CD4 and anti-CD8 antibodies. In either case, after two final washings, cells were fixed in PBS with $1 \%$ formaldehyde. For staining of monocytes/ macrophages appropriate amounts of monoclonal antibodies and $100 \mu 1$ PBS-EDTA were added to the pellets and the cells were incubated on ice for 30 minutes. Irrelevant mouse IgG antibodies of the same isotype and concentration were used as controls. After two washes cells were fixed in $1 \%$ paraformaldehyde. All alveolar macrophage samples were from non-smokers to avoid increased background due to autofluorescence. ${ }^{9}$

Cells were analysed in a flow cytometer (FACSort, Becton Dickinson, Mountain View, California, USA). Lymphocytes were gated by forward and side scatters and the percentages of 
positively labelled cells in the CD4+ and CD8+ subsets were scored. Isotype matched negative control antibodies always stained less than $1 \%$ of CD4+ and CD8+ lymphocytes. Peripheral blood monocytes and alveolar macrophages were also gated by light scattering properties. Quantitative levels of respective antigen, expressed as mean fluorescence intensity (MFI), were determined after subtraction of the background level calculated from samples labelled with control antibodies. Since the positioning of the cut off marker for background fluorescence tended to be more subjective for these cell types than for lymphocytes, we decided to present the data as only MFI values.
CORRELATIONS BETWEEN IMMUNE CELL PHENOTYPES AND CELL SUBSET PROPORTIONS We investigated whether BAL $\mathrm{T}$ cell expression of the co-stimulatory molecule CD28 correlated with paired alveolar macrophage expression of ligands CD80 and CD86, and whether BAL T cell expression of CD54 correlated with alveolar macrophage expression of the ligands CD11a and CD11b. The relation of $T$ cell CD11a expression to that of alveolar macrophage CD54 was not investigated since, in all cases, more than $99 \%$ of $\mathrm{T}$ cells were positive for CD11a. Any correlation of alveolar macrophage phenotype or BAL CD4/CD8 ratio with proportions of BAL cells was also investigated.
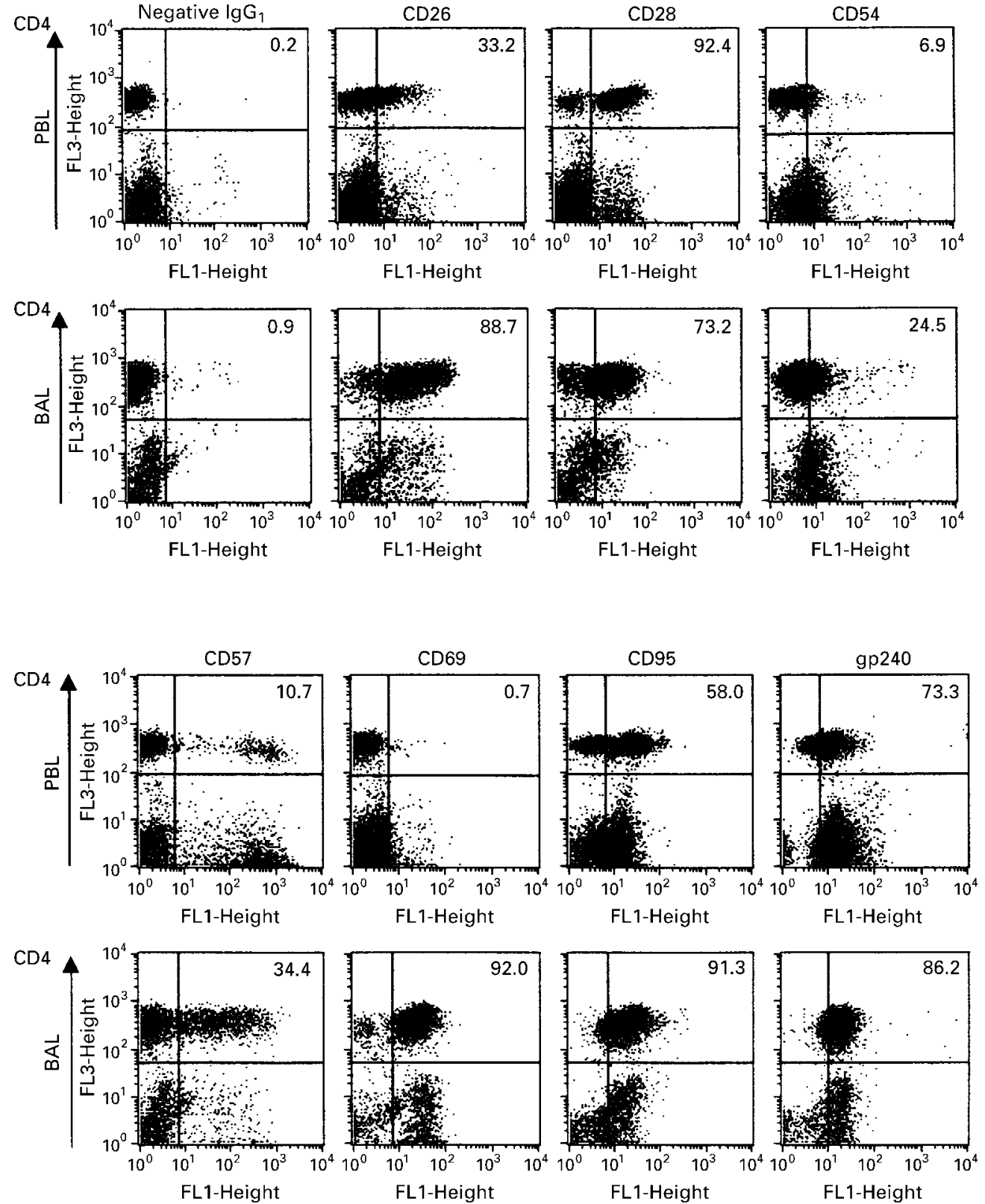

Figure 1 Flow cytometry dot plots of PBL and BAL lymphocytes from a representative patient. Cells were stained with FITC labelled antibodies against various cell surface markers ( $x$ axis), RPE-Cy5 labelled antibodies against CD 4 (y axis), and RPE labelled antibodies against CD8 (data not shown). The number in each upper right quadrant denotes the percentage of CD4+ lymphocytes positive for the respective marker. For CD57 (IgM) and gp240 (IgG2a) separate isotype matched controls were used, yielding a background similar to that of $\operatorname{Ig}_{1}$. 


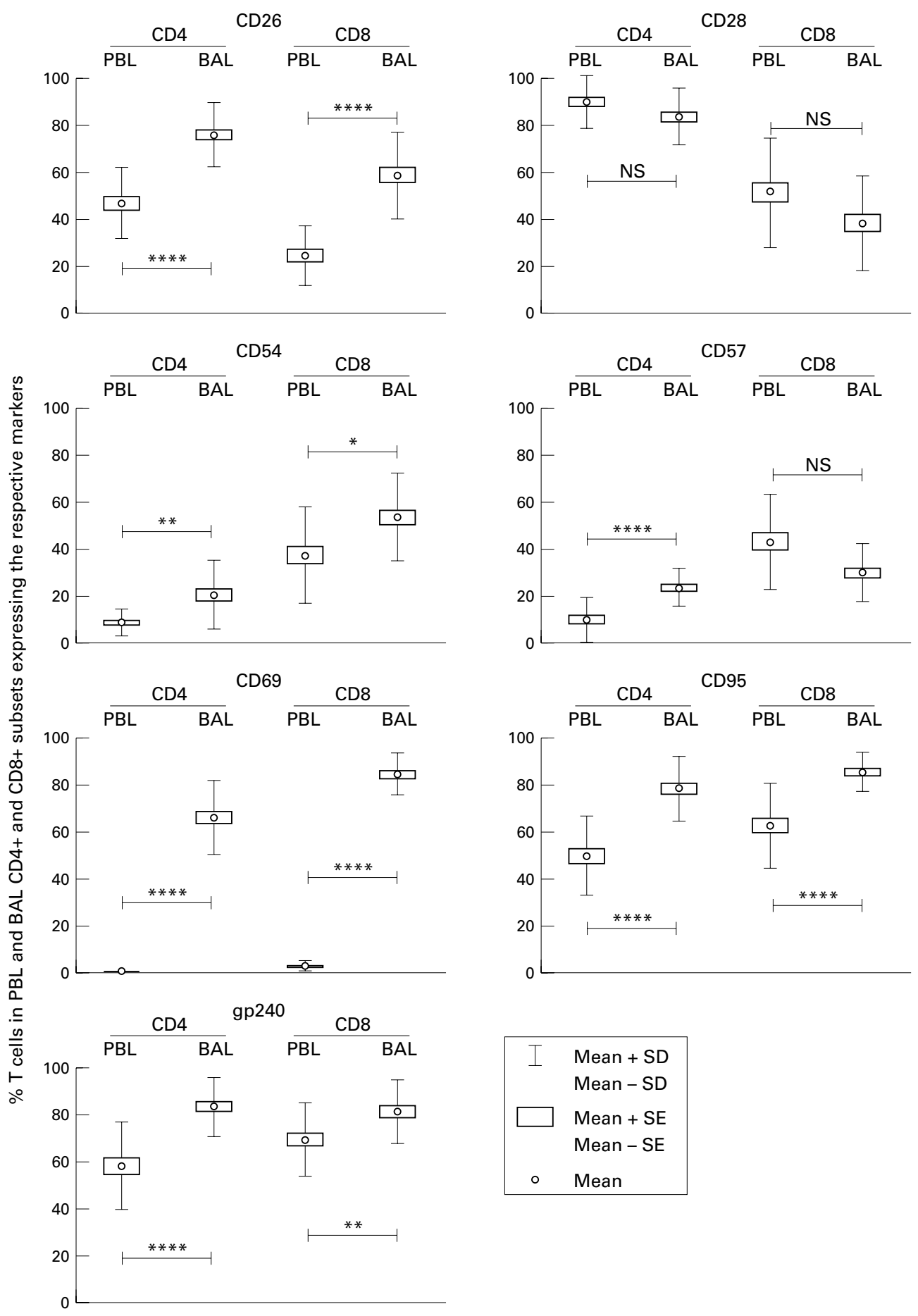

Figure 2 Immunophenotyping of T cell subsets. Percentage of cells in PBL CD4+, BAL CD4+, PBL CD8+ and BAL $C D 8+$ subsets expressing the respective antigens. $p$ values for comparisons of $P B L$ and BAL fluid samples are indicated: ${ }^{\star} p<0.05,{ }^{\star *} p<0.01,{ }^{\star \star *} p<0.001,{ }^{\star \star \star *} p<0.0001$.

STATISTICAL ANALYSIS

Results are presented as mean (SD) values. Significance levels were calculated according to the non-parametric Mann-Whitney $U$ test. The Pearson $r$ correlation coefficient was determined and tested for statistical significance. A p value of $<0.05$ was regarded as significant.

\section{Results}

LYMPHOCYTES

Total and differential cell counts for BAL fluid and $\mathrm{CD} 4 / \mathrm{CD} 8$ ratios in BAL fluid and PBL are shown in table 2 . The CD4/CD8 ratio was significantly higher in BAL fluid than in PBL for patients with active disease who also had a higher BAL CD4/CD8 ratio and a higher percentage of BAL lymphocytes $(27.4 \%$ versus $14.8 \%, \mathrm{p}=0.03$ ) than those with inactive disease.

An example of flow cytometry analysis of PBL and BAL $T$ cells is shown in fig 1. Table 3 and fig 2 present the phenotypic analysis of lymphocytes, expressed as percentage of positive cells in each of the subsets PBL CD4, 
Table 3 Immunophenotyping of $T$ cell subsets

\begin{tabular}{|c|c|c|c|c|c|c|}
\hline & $P B L C D 4$ & $P B L C D 8$ & $B A L C D 4$ & $B A L C D 8$ & $P B L$ vs $B A L$ & $C D 4$ vs $C D 8$ \\
\hline CD26 & $46.1(15.1)$ & $24.1(12.6)$ & $74.9(13.4)$ & $58.0(18.0)$ & $\begin{array}{l}\mathrm{p}<0.0001(\mathrm{CD} 4) \\
\mathrm{p}<0.0001(\mathrm{CD} 8)\end{array}$ & $\begin{array}{l}\mathrm{p}<0.0001(\mathrm{PBL}) \\
\mathrm{p}<0.01(\mathrm{BAL})\end{array}$ \\
\hline CD28 & $89.1(11.0)$ & $51.1(23.0)$ & $83.0(11.8)$ & $38.8(20.0)$ & $\begin{array}{l}\text { NS (0.06) (CD4) } \\
\text { NS (CD8) }\end{array}$ & $\begin{array}{l}\mathrm{p}<0.0001(\mathrm{PBL}) \\
\mathrm{p}<0.0001(\mathrm{BAL})\end{array}$ \\
\hline CD54 & $8.5(5.8)$ & $37.2(20.5)$ & $20.4(14.9)$ & $53.8(19.0)$ & $\begin{array}{l}\mathrm{p}<0.01(\mathrm{CD} 4) \\
\mathrm{p}<0.05(\mathrm{CD} 8)\end{array}$ & $\begin{array}{l}\mathrm{p}<0.0001(\mathrm{PBL}) \\
\mathrm{p}<0.0001(\mathrm{BAL})\end{array}$ \\
\hline CD57 & $10.0(9.7)$ & $43.6(20.5)$ & $23.8(8.1)$ & $30.6(12.1)$ & $\begin{array}{l}\mathrm{p}<0.0001(\mathrm{CD} 4) \\
\mathrm{NS}(0.06)(\mathrm{CD} 8)\end{array}$ & $\begin{array}{l}\mathrm{p}<0.0001(\mathrm{PBL}) \\
\mathrm{NS}(0.06)(\mathrm{BAL})\end{array}$ \\
\hline CD69 & $1.0(1.2)$ & $3.7(2.5)$ & $66.5(15.8)$ & $84.9(8.7)$ & $\begin{array}{l}\mathrm{p}<0.0001(\mathrm{CD} 4) \\
\mathrm{p}<0.0001(\mathrm{CD} 8)\end{array}$ & $\begin{array}{l}\mathrm{p}<0.0001(\mathrm{PBL}) \\
\mathrm{p}<0.0001(\mathrm{BAL})\end{array}$ \\
\hline CD95 & $49.9(16.6)$ & $63.4(18.0)$ & $78.6(13.8)$ & $86.3(8.4)$ & $\begin{array}{l}\mathrm{p}<0.0001(\mathrm{CD} 4) \\
\mathrm{p}<0.0001(\mathrm{CD} 8)\end{array}$ & $\begin{array}{l}\mathrm{p}<0.05(\mathrm{PBL}) \\
\mathrm{NS}(0.08)(\mathrm{BAL})\end{array}$ \\
\hline gp240 & $58.3(18.9)$ & $70.5(15.6)$ & $83.9(12.4)$ & $82.5(13.7)$ & $\begin{array}{l}\mathrm{p}<0.0001(\mathrm{CD} 4) \\
\mathrm{p}<0.01(\mathrm{CD} 8)\end{array}$ & $\begin{array}{l}\mathrm{p}<0.05(\mathrm{PBL}) \\
\mathrm{NS}(\mathrm{BAL})\end{array}$ \\
\hline
\end{tabular}

Mean (SD) percentage of cells in peripheral blood (PBL) and bronchoalveolar lavage (BAL) lymphocyte subsets expressing the respective antigens are given, together with $\mathrm{p}$ values for comparisons between cell subsets.

Significant differences between patient groups (active/inactive disease, A/IA): CD54 PBL CD4 A/IA 6.4/12.8 ( $<<0.05)$.

Tendencies $(0.05<\mathrm{p}<0.1)$ to differences between groups: CD54 PBL CD8 A/IA 32.1/47.6 (p = 0.08); gp240 PBL CD4 A/IA 52.8/ $67.2(\mathrm{p}=0.08)$.

PBL CD8, BAL CD4 and BAL CD8. Surface markers studied were the activation markers CD26 (a proposed Th1 marker), CD69, CD95 (also known as Fas, ligation of which induces programmed cell death) and gp240. ${ }^{10}$ The expression of CD28 (costimulatory), CD54 (adhesion), and CD57 (subset marker) was also investigated. These markers were expressed by a higher percentage of BAL than PBL cells in both the CD4+ and CD8+ subsets, being most dramatic for CD69. The only exception was CD28 which tended to be relatively underexpressed by BAL CD4+ and CD8+ cells. CD57 deviated from the general pattern, being overexpressed by BAL CD4+ compared with PBL CD4+ cells, but with a tendency towards to a lower expression in BAL CD8 than in PBL CD8 cells. With regard to differences between CD4 and CD8, CD26 and CD28 were preferentially expressed by CD4+ cells in both PBL and BAL fluid, while the other markers were generally expressed by a higher percentage of CD8+ cells.

The transferrin receptor CD71, costimulatory molecules CD80 and CD86, and the inhibitory receptor CTLA-4 were expressed by very small subsets of cells, with few exceptions by less than $5 \%$ of the cells (data not included). CD11a (LFA-1) and CD50 were in all cases expressed by more than $99 \%$ of lymphocytes in all subsets.
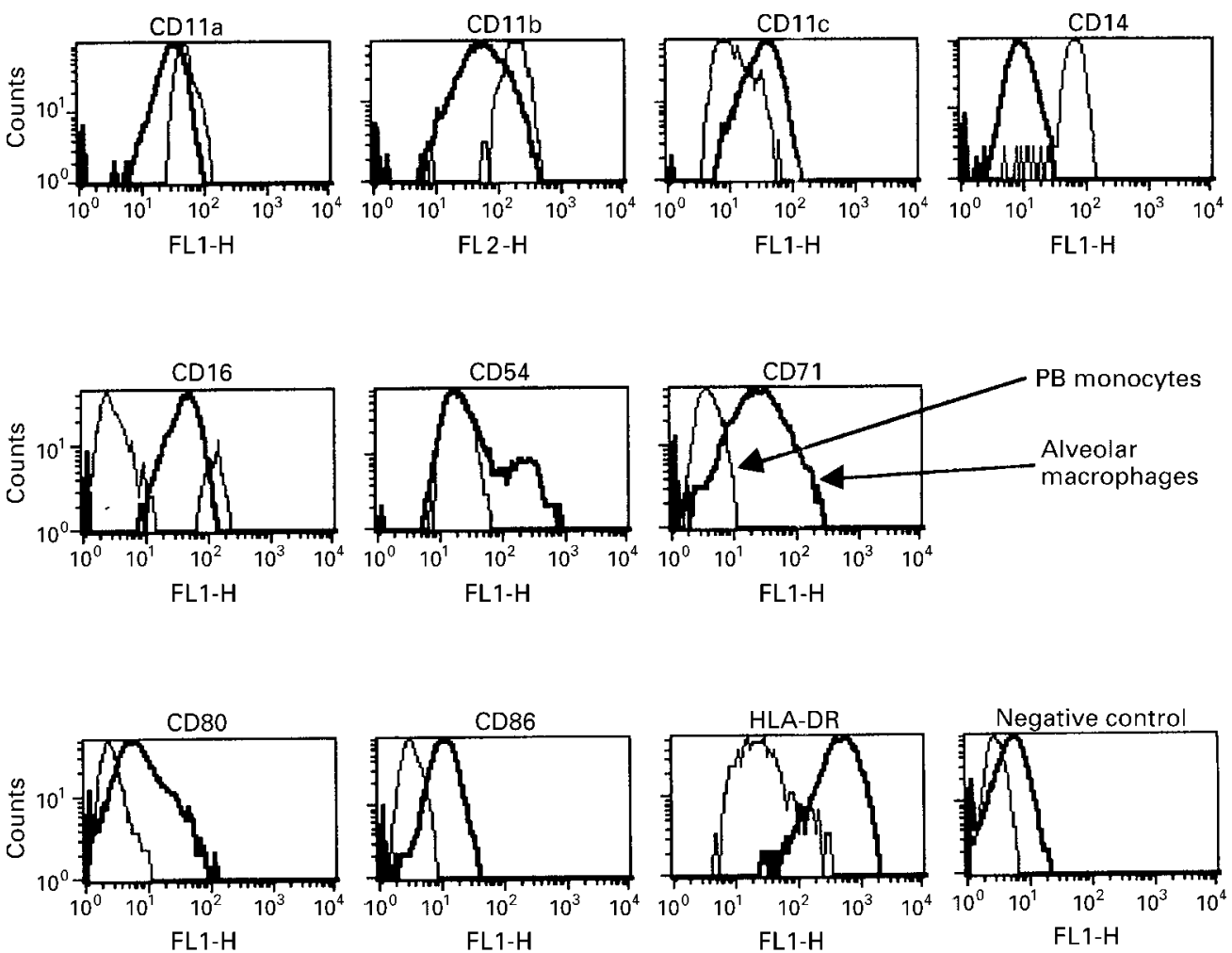

Figure 3 Comparative histogram analysis of the expression of cell surface markers by peripheral blood (PB) monocytes (thin lines) and alveolar macrophages (thick lines) from paired samples recovered from one patient. On the $x$ axis is the relative fluorescence on a logarithmic scale for a given marker and the y axis shows the relative number of events. Several isotype matched controls were used; the negative control for CD14 shown is a representative example. 
Table 4 Immunophenotyping of peripheral blood (PB) monocytes and alveolar macrophages (AM)

\begin{tabular}{lccl}
\hline & PB monocytes & AM & PB monocytes vs $A M$ \\
\hline CD11a & $51.9(8.0)$ & $31.8(4.0)$ & $\mathrm{p}<0.0001$ \\
CD11b & $268.1(140.2)$ & $80.5(29.0)$ & $\mathrm{p}<0.0001$ \\
CD11c & $16.0(5.0)$ & $25.3(5.4)$ & $\mathrm{p}<0.0001$ \\
CD14 & $57.8(18.8)$ & $4.8(1.3)$ & $\mathrm{p}<0.0001$ \\
CD16 & $29.9(9.2)$ & $51.1(13.8)$ & $\mathrm{p}<0.0001$ \\
CD54 & $25.7(7.2)$ & $70.1(33.8)$ & $\mathrm{p}<0.0001$ \\
CD71 & $1.8(1.4)$ & $55.2(29.2)$ & $\mathrm{p}<0.0001$ \\
CD80 & $2.0(2.6)$ & $5.0(6.9)$ & $\mathrm{p}<0.0001$ \\
CD86 & $0.7(0.6)$ & $4.3(2.1)$ & $\mathrm{p}<0.01$ \\
HLA-DR & $59.9(12.9)$ & $401.1(78.8)$ & $\mathrm{p}<0.0001$ \\
\hline
\end{tabular}

Values depict mean (SD) fluorescence intensities and $\mathrm{p}$ values for comparisons between cell subsets.

Significant differences between patient groups (A/IA = active/inactive disease): CD11a PB monocytes A/IA 53.9/46.9 $(\mathrm{p}<0.05)$; CD11a AM A/IA 33.2/28.1 ( $\mathrm{p}<0.05)$.

PERIPHERAL BLOOD MONOCYTES AND ALVEOLAR MACROPHAGES

The results from immunophenotyping of peripheral blood monocytes and alveolar macrophages are shown for a representative patient in fig 3 and are summarised in table 4 . The adhesion molecules CD11a and CD11b, both $\beta_{2}$ integrins, and the LPS receptor CD14 were expressed to a higher degree in monocytes. In contrast, macrophages had a higher expression of adhesion molecule CD11c, CD71 (transferrin receptor), HLA class II, CD16 (Fc $\gamma$ receptor type III), CD54 (ICAM-1) and the co-stimulatory molecules CD80 and CD86.

COMPARISONS BETWEEN PATIENT GROUPS

In both peripheral blood monocytes and alveolar macrophages the expression of adhesion molecule CD11a (LFA-1) was higher in those with active disease (table 4). Active disease was also associated with fewer PBL CD4+ $\mathrm{T}$ cells positive for CD54, with a similar trend in PBL CD8 (table 3).

CORRELATIONS BETWEEN IMMUNE CELL PHENOTYPES AND CELL SUBSET PROPORTIONS There was a positive correlation between total cell count and percentage lymphocytes $(r=$ $0.503, p=0.007)$. Focusing on the receptorligand pairs CD28-CD80/CD86 (costimulation) and CD54-CD11a/CD11b (adhesion), we determined that the frequencies of CD4+ and CD8+ T cells positive for CD28 or CD54 did not correlate with alveolar macrophage expression of their respective ligands, neither in the total group of patients nor in any subgroup (active/inactive disease). Investigating relations between $\mathrm{T}$ cell or alveolar macrophage phenotype and immune cell proportions, however, we detected an association between alveolar macrophage expression of CD11a and the percentage of BAL lymphocytes $(r=0.625, \mathrm{p}=0.004)$, in line with our findings of increased expression of CD11a in alveolar macrophages and BAL lymphocytosis in active disease. There was also a positive correlation between CD80 expression in alveolar macrophages and the BAL CD4/CD8 ratio $(r=0.674, \mathrm{p}=0.006)$.

\section{Discussion}

In this study we have analysed the phenotype of CD4+ and CD8+ T lymphocytes from PBL and BAL fluid, as well as peripheral blood monocytes and alveolar macrophages from patients with sarcoidosis. Cells were studied with respect to expression of various surface activation markers, co-stimulatory and adhesion molecules. In addition, we investigated differences between cells from patients with active and inactive disease.

Our results highlight the role of $\mathrm{T}$ cells in sarcoidosis as there was an increased expression by BAL lymphocytes of several of the molecules studied-for example, CD26, CD95 (Fas), and the activation markers CD69 and gp240. This is in agreement with previous studies investigating other activation markers such as IL-2R (CD25), very late activation antigen-1 (VLA-1), CD49a, CD49d, and HLA-DR. ${ }^{11-14}$ A role for the receptor-ligand adhesion molecule pair CD11a/CD18-CD54 is indicated by our demonstration of increased expression of CD11a on alveolar macrophages as well as on peripheral blood monocytes in active disease, correlating with the percentage of BAL lymphocytes.

The increased prevalence of lymphocytes positive for CD26 in BAL fluid suggests chronic $\mathrm{T}$ cell stimulation in the lung. Interestingly, CD26 has been implicated as a marker for Th1 cells since it was expressed by IFN $\gamma$-producing cells in tuberculoid leprosy and in sarcoidosis. ${ }^{15}$ The increased expression of CD26 on BAL T cells therefore agrees with the suggested Th1 profile of the inflammatory response in sarcoidosis. ${ }^{16}$ Interestingly, the frequency of CD26+ cells in PBL appears to be increased compared with values reported for healthy controls, ${ }^{10}$ similar to the situation in rheumatoid arthritis. ${ }^{17}$ The only lymphocyte marker studied with a tendency to reduced expression in BAL fluid was CD28, which is regarded as a most important co-stimulatory molecule for T cells. Since we also detected a higher percentage of CD28 negative cells in the peripheral blood CD4+ subset compared with healthy controls, ${ }^{18}$ it appears that CD28 expression is reduced on CD4+ cells in both PBL and BAL fluid of patients with sarcoidosis. A reduced expression of CD28 has been proposed to be associated with replicative senescence, a state reached by the $\mathrm{T}$ lymphocyte after multiple cell divisions and characterised by shortened telomeres and diminished or altered effector functions. ${ }^{19}$ It has been reported, moreover, that clonal expansions of CD8 + T lymphocytes preferentially belong to the CD28 negative $\mathrm{T}$ cell subset. ${ }^{20} \mathrm{~A}$ reduced expression of CD28, indicating $\mathrm{T}$ cell senescence, has been reported in the peripheral blood of patients with rheumatoid arthritis ${ }^{21}$ and a decreased co-stimulation of CD4+ cells via CD28 was recorded in patients with Crohn's disease. ${ }^{22}$ Our finding of a tendency towards reduced expression of CD28 on T cells in BAL fluid compared with those in PBL of patients with sarcoidosis is therefore in agreement with a local chronic stimulation of $\mathrm{T}$ cells, eventually generating functionally impaired (or functionally altered) end stage $\mathrm{T}$ cells. The diminished antigen induced proliferative response of lung $\mathrm{T}$ cells 
from patients with sarcoidosis ${ }^{23}$ may be related to this finding.

Clonal expansions of $\mathrm{T}$ cells that can be detected both in healthy individuals and in various diseases, in addition to lacking CD28, preferentially occur within CD4+CD57+ or CD8+CD57+ subsets. $^{2425}$ The number of peripheral blood CD57+ cells is increased in various diseases such as rheumatoid arthritis ${ }^{26}$ and cytomegalovirus infection. ${ }^{27}$ Little is known about the functional role of this molecule, but a suppressive role for alveolar CD8+ CD57+ cells has been described in HIV infected individuals. ${ }^{28}$ In our patient group there were somewhat more CD4+ CD57+ cells in BAL fluid than in PBL, but fewer CD8+ $\mathrm{CD} 57+$. This agrees with our previous findings of oligoclonal BAL CD4+ AV2S3+ (Va2.3+ employing the old nomenclature for $\mathrm{T}$ cell receptors) expansions in HLA-DR17+ patients with sarcoidosis in Scandinavia. ${ }^{29}$ Compared with previous reports of CD57 expression in $\mathrm{PBL}^{24}$ and BAL fluid ${ }^{30}$ of healthy individuals, however, the frequencies of CD57+ cells in patients with sarcoidosis were clearly increased, particularly in BAL fluid.

CD69, an early activation marker, was virtually absent from PBL as expected, but expressed to a high degree by both BAL CD4+ and CD8+ $\mathrm{T}$ cells, consistent with an earlier report in which increased expression of CD69 on BAL cells of healthy controls was found with even higher levels in patients with sarcoidosis. ${ }^{31}$ Not only the induction of an immune response but also its termination is of critical importance in the maintenance of homeostasis. In this respect CD95, also known as Fas, has received much attention since triggering via this molecule activates the cellular programme for suicide, apoptosis, which may be critical for limiting an inflammatory response. $^{32}$ Indeed, more CD4+ and CD8+ cells were positive for CD95 in BAL fluid than in PBL. The significance of this is not clear since apoptosis of BAL lymphocytes in vitro does not seem to be mediated by Fas, and CD95 expression is associated with stimulation of the T cells. ${ }^{33}$ Increased expression of CD95 on BAL $\mathrm{T}$ cells from healthy controls and patients with sarcoidosis, and on PBL T cells from patients with sarcoidosis has previously been reported. ${ }^{33}$ In contrast, Agostini et al detected an increased expression of CD95 on BAL $T$ cells from patients with sarcoidosis compared with healthy controls. ${ }^{34}$ Previous studies performed on PBL samples from healthy controls have reported an overall lower level of expression of CD $54^{35}$ and gp $240^{10}$ than in this study. This should be interpreted with caution, however, and may be due to differences in the exact epitope recognised or staining protocols.

The most notable difference between patients with active and inactive disease was the increased expression of adhesion molecule CD11a on both peripheral blood monocytes and alveolar macrophages of patients with active disease. Previous studies have shown an increased number of alveolar macrophages positive for CD11a and/or CD11b in patients with sarcoidosis compared with healthy controls. ${ }^{36-38}$ The increased level of CD11a has been suggested as an explanation for the increased antigen presenting capacity of alveolar macrophages from patients with sarcoidosis. ${ }^{5}$ CD11a was required for the binding of specific $\mathrm{T}$ cell clones to alveolar macrophages and an increased surface density of CD11a correlated with an ability to stimulate $\mathrm{T}$ cells. ${ }^{2}$ Our finding of a positive correlation between CD11a expression on alveolar macrophages and the percentage of BAL lymphocytes supports the notion that CD11a is crucial in attracting and stimulating $\mathrm{T}$ cells. The presence of fewer PBL CD54+ cells in active disease may also reflect recruitment to the lung, aided by interactions between CD11a and CD54. CD54 is another adhesion molecule that was previously found to be expressed by increased numbers of alveolar macrophages in patients with sarcoidosis, ${ }^{36-38}$ particularly during active disease. ${ }^{36}{ }^{39}$ For most cell surface markers studied, however, there were no statistically significant differences between active and inactive disease. This may be due to a similar inflammatory activity in the lungs of patients not displaying symptoms, or because of insufficiently large patient groups.

Our study indicates rather low MFI values for the surface molecules CD80 and CD86, although this may be sufficient for costimulatory activities. Earlier investigations evaluating the percentage of positive alveolar macrophages have found increased numbers of CD80 and CD86 positive alveolar macrophages in patients with sarcoidosis, ${ }^{16}{ }^{40}$ in sharp contrast to findings in healthy controls. ${ }^{41}$ It is worth noting, however, that a strong CD80/86 expression of alveolar macrophages from healthy controls has also been reported. ${ }^{42} \mathrm{We}$ determined a positive correlation between CD80 expression on alveolar macrophages and BAL CD4/CD8 ratio, perhaps related to a predominantly Th1 type inflammation in CD4+ dominated alveolitis in sarcoidosis, since CD80 has been suggested to be associated with Th1 responses.

The higher expression of CD11a, CD11b, and CD14 in peripheral blood monocytes and of CD11c, CD71, and HLA class II in alveolar macrophages agrees with alterations in phenotype reflecting the maturation of monocytes into macrophages, ${ }^{43}$ but is in contrast to other reports on CD $11 \mathrm{~b},{ }^{44}$ possibly due to differing cell preparation methods. Levels of CD11b and CD14 on alveolar macrophages, expressed as MFI values, did not differ between patient groups, although earlier studies have described increased proportions of alveolar macrophages positive for $\mathrm{CD} 11 \mathrm{~b}^{36}{ }^{39}$ and for $\mathrm{CD} 14^{46}$ in patients with active sarcoidosis.

Further insights into the pathogenic roles of different cell subsets, as well as establishment of markers of disease activity, may be gained by studying various macrophage subsets separately. We are now pursuing this matter in parallel with investigating cytokine production by different $\mathrm{T}$ cell subsets in different patient groups. 
In conclusion, our data reveal substantial activation of CD4+ and CD8+ lung $\mathrm{T}$ cells from patients with sarcoidosis. The phenotypic profile is consistent with increased numbers of clonally/oligoclonally expanded end stage maturation Th1 cells. The alterations in adhesion molecule usage and corresponding lung cell subset compositions apparent in active disease aid our understanding of the macrophage/ $\mathrm{T}$ cell interplay underlying the pulmonary pathology and clinical manifestations of sarcoidosis. Long term follow up may reveal a possible prognostic value of the cell surface expression of some of the markers studied.

The authors thank Marie Hallgren, Benita Dahlberg, Margitha Dahl, and Gunnel de Forest for skilful technical assistance and Dr R A Harris for linguistic advice. The support of the Swedish Heart-Lung Foundation, the Swedish Medical Research Council, the Swedish Society of Medicine, and Karolinska Institutet is gratefully acknowledged.

1 Newman L, Rose C, Maier L. Medical progress: sarcoidosis. N Engl f Med 1997;336:1224-33.

2 Lyons C, Ball E, Toews G, et al. Inability of human alveolar macrophages to stimulate resting $\mathrm{T}$ cells correlates with decreased antigen-specific $\mathrm{T}$ cell-macrophage binding. $\mathcal{f}$ Immunol 1986;137:1173-80.

3 Strickland D, Thepen T, Kees U, et al. Regulation of T-cell function in lung tissue by pulmonary alveolar macrofunction in lung tissue by pulmon

phages. Immunology 1993;80:266-72.
4 Lem V, Lipscomb M, Weissler J, et al. Bronchoalveolar cells from sarcoid patients demonstrate enhanced antigen presentation. F Immunol 1985;135:1766-71.

5 Ina Y, Takada K, Yamamoto $M$, et al. Antigen-presenting capacity in patients with sarcoidosis. Chest 1990;98:911-6.

6 Costabel U. CD4/CD8 ratios in bronchoalveolar lavage fluid: of value for diagnosing sarcoidosis? Eur Respir $\mathscr{f}$ 1997;10:2699-700

7 Costabel U, du Bois R, Eklund A, et al. Consensus conference: activity of sarcoidosis. Third WASOG Meet-
ing, Los Angeles, USA, 8-11 September 1993. Eur Respir F 1994;7:624-7.

8 Eklund A, Blaschke E. Relationship between changed alveolar-capillary permeability and angiotensin converting enzyme activity in serum in sarcoidosis. Thorax 1986;41: 629-34.

9 Sköld C, Lundahl J, Halldén G, et al. Chronic smoke exposure alters the phenotype pattern and the metabolic response in human alveolar macrophages. Clin Exp response in human alveolar

10 Ulmer A, Mattern T, Feller A, et al. CD26 antigen is a surface dipeptidyl peptidase IV (DPPIV) as characterized by monoclonal antibodies clone TII-19-4-7 and 4EL1C7. Scand F Immunol 1990;31:429-35.

11 Müller-Quernheim J, Saltini C, Sondermeyer P, et al. Compartmentalized activation of the interleukin 2 gene by lung T lymphocytes in active pulmonary sarcoidosis. F Immunol 1986;137:3475-83.

12 Saltini C, Hemler M, Crystal R. T lymphocytes compartmentalized on the epithelial surface of the lower respiratory tract express the very late activation antigen complex VLA-2. Clin Immunol Immunopathol 1988;46:221-33.

13 Saltini C, Spurzem J, Lee J, et al. Spontaneous release of interleukin-2 by lung $\mathrm{T}$ lymphocytes in active pulmonary sarcoidosis is primarily from the LEU3+DR+ T cell sarcoidosis is primarily from the 1 Clin Invest $1986 ; 77: 1962-70$.

14 Berlin M, Lundahl M, Sköld C, et al. The lymphocytic alveolitis in sarcoidosis is associated with increased amounts of soluble and cell bound adhesion molecules in bronchoalveolar lavage fluid and serum. f Int Med bronchoalveolar

15 Scheel-Toellner D, Richter E, Toellner K, et al. CD26 expression in leprosy and other granulomatous diseases correlates with the production of interferon- $\gamma$. Lab Invest 1995;73:685-90.

16 Hoshino $\mathrm{T}$, Itoh $\mathrm{K}$, Gouhara $\mathrm{R}$, et al. Spontaneous production of various cytokines except IL- 4 from CD4+ T cells in the affected organs of sarcoidosis patients. Clin Exp Immunol 1995;102:399-405.

17 Gerli R, Muscat C, Bertotto A, et al. CD26 surface molecule involvement in $\mathrm{T}$ cell activation and lymphokine synthesis in rheumatoid and other inflammatory synovitis. Clin Immunol Immunopathol 1996;80:31-7.

18 Choremi-Papadopoulou H, Viglis V, Gargalianos P, et al. Downregulation of CD28 surface antigen on CD4+ and CD8+ T lymphocytes during HIV-1 infection. F AIDS 1994;7:245-53.

19 Effros R, Pawelec G. Replicative senescence of T cells: does the Hayflick limit lead to immune exhaustion? Immunol Today 1997;18:450-4.

20 Batliwalla F, Monteiro J, Serrano D, et al. Oligoclonality of $\mathrm{CD} 8+\mathrm{T}$ cells in health and disease: aging, infection, or immune regulation? Hum Immunol 1996;48:68-76.
21 Schmidt D, Goronzy J, Weyand C. CD4+ CD7- CD28- T cells are expanded in rheumatoid arthritis and are characterized by autoreactivity. F Clin Invest 1996;97:2027-37.

22 Roman L, Manzano L, De La Hera A, et al. Expanded CD4+ CD45RO+ phenotype and defective proliferative response in T lymphocytes from patients with Crohn's disease. Gastroenterology 1996;110:1008-19.

23 Lecossier D, Valeyre D, Loiseau A, et al. Antigen-induced proliferative response of lavage and blood T lymphocytes. Am Rev Respir Dis 1991;144:861-8.

24 Serrano D, Monteiro J, Allen S, et al. Clonal expansion within the CD4+CD57+ and CD8+CD57+ T cell subsets in chronic lymphocytic leukemia. F Immunol 1997;158: 1482-9.

25 Morley J, Batliwalla F, Hingorani R, et al. Oligoclonal CD8+ $T$ cells are preferentially expanded in the CD57+ subset. $\mathcal{F}$ Immunol 1995;154:6182-90.

26 Dupuy D'Angeac A, Monier S, Jorgensen C, et al. Increased percentage of CD3+, CD57+ lymphocytes in patients with heumatoid arthritis: correlation with duration of disease. Arthritis Rheum 1993;36:608-12.

27 Hazzan M, Labalette M, Noel C, et al. Recall response to cytomegalovirus in allograft recipients: mobilization of CD 57+, CD28+ cells before expansion of CD57+, CD28cells within the CD8+ T lymphocyte compartment. Transplantation 1997;63:693-8.

28 Sadat-Sowti B, Parrot A, Quint L, et al. Alveolar CD8+ CD57+ lymphocytes in human immunodefiency virus infection produce an inhibitor of cytotoxic functions. Am $\mathcal{F}$ Respir Crit Care Med 1994;149:972-80.

29 Grunewald J, Hultman T, Bucht A, et al. Restricted usage of $T$ cell receptor $V \alpha / J \alpha$ gene segments with different nucleotide but identical amino acid sequences in HLADR3+ sarcoidosis patients. Mol Med 1995;1:287-96.

30 Ancochea J, González A, Sánchez M, et al. Expression of lymphocyte activation surface antigens in bronchoalveolar lavage and peripheral blood cells from young healthy subjects. Chest 1993;104:32-7.

31 Hol B, Hintzen R, Van Lier R, et al. Soluble and cellular markers of $\mathrm{T}$ cell activation in patients with pulmonary sarcoidosis. Am Rev Respir Dis 1993;148:643-9.

32 Van Parijs L, Ibraghimov A, Abbas A. The roles of costimulation and Fas in T cell apoptosis and peripheral tolerance. Immunity 1996;4:321-8.

33 Herry I, Bonay M, Bouchonnet F, et al. Extensive apoptosis of lung T-lymphocytes maintained in vitro. Am $\mathcal{F}$ Respir Cell Mol Biol 1996;15:339-47.

34 Agostini C, Zambello R, Sancetta R, et al. Expression of tumor necrosis factor-receptor superfamily members by lung T lymphocytes in interstitial lung disease. Am f Respir Crit Care Med 1996;153:1359-67.

35 Roussel E, Gingras M-C, Grimm E, et al. High expression of adhesion molecules/activation markers with little interleukin-2, interferon $\gamma$, and tumor necrosis factor $\beta$ gene activation in fresh tumor-infiltrating lymphocytes from lung adenocarcinoma. Cancer Immunol Immunother 1995;41:1-9.

36 Striz I, Wang Y-M, Kalaycioglu O, et al. Expression of alveolar macrophage adhesion molecules in pulmonary sarcoidosis. Chest 1992;102:882-6.

37 Schaberg T, Rau M, Stephan H, et al. Increased number of alveolar macrophages expressing surface molecules of the CD11/CD18 family in sarcoidosis and idiopathic pulmonary fibrosis is related to the production of superoxide anions by these cells. Am Rev Respir Dis 1993;147:1507-13.

38 Melis M, Giomarkaj M, Pace E, et al. Increased expression of leukocyte function associated antigen-1 (LFA-1) and intercellular adhesion molecule-1 (ICAM-1) by alveolar macrophages of patients with pulmonary sarcoidosis. Chest 1991;100:910-6.

39 Striz I, Wang Y, Svarcova I, et al. The phenotype of alveolar macrophages and its correlation with immune cells in bronchoalveolar lavage. Eur Respir f 1993;6:1287-94.

40 Nicod L, Isler P. Alveolar macrophages in sarcoidosis coexpress high levels of CD86 (B7.2), CD40 and CD30L. Am 7 Respir Cell Mol Biol 1997;17:91-6.

41 Chelen C, Fang Y, Freeman G, et al. Human alveolar macrophages present antigen ineffectively due to defective expression of B7 costimulatory cell surface molecules. $f$ Clin Invest 1995;95:1415-21.

42 Soler P, Bousaud V, Moreau J, et al. Normal lung macrophages and epithelioid cells in tuberculosis and sarcoid granulomas express B7 molecules. Am f Respir Crit Care Med 1997;155:A982.

43 Prieto J, Eklund A, Patarroyo M. Regulated expression of integrins and other adhesion molecules during differentiation of monocytes into macrophages. Cell Immunol 1994;156:191-211.

44 Lundahl J, Halldén G, Sköld C. Human blood monocytes, but not alveolar macrophages, reveal increased CD11b/ CD18 expression and adhesion properties upon receptordependent activation. Eur Respir f 1996;9:1188-94.

45 Gessani S, Testa U, Varano B, et al. Enhanced production of LPS-induced cytokines during differentiation of human monocytes to macrophages. F Immunol 1993;151:3758-66.

46 Striz I, Wang Y, Teschler H, et al. Phenotypic markers of alveolar macrophage maturation in pulmonary sarcoidosis. Lung 1993;171:293-303. 